\title{
ASO Visual Abstract: Improvement in Breast Reconstruction Disparities Following Medicaid Expansion Under the Affordable Care Act
}

Kirithiga Ramalingam, MD, Liang Ji, DrPh, MBA, Saeed Pairawan, MD, David Caba Molina, MD, MS, MPH, and Sharon S. Lum, MD

Loma Linda University Health, Loma Linda, CA

Reduction in disparities in breast reconstruction followed Medicaid expansion under the Affordable Care Act (https://doi.org/10.1245/s10434-021-10495-z). Mitigation of disparities was not achieved in states that did not expand Medicaid.
DISCLOSURES The authors have no disclosures to report.

Publisher's Note Springer Nature remains neutral with regard to jurisdictional claims in published maps and institutional affiliations.

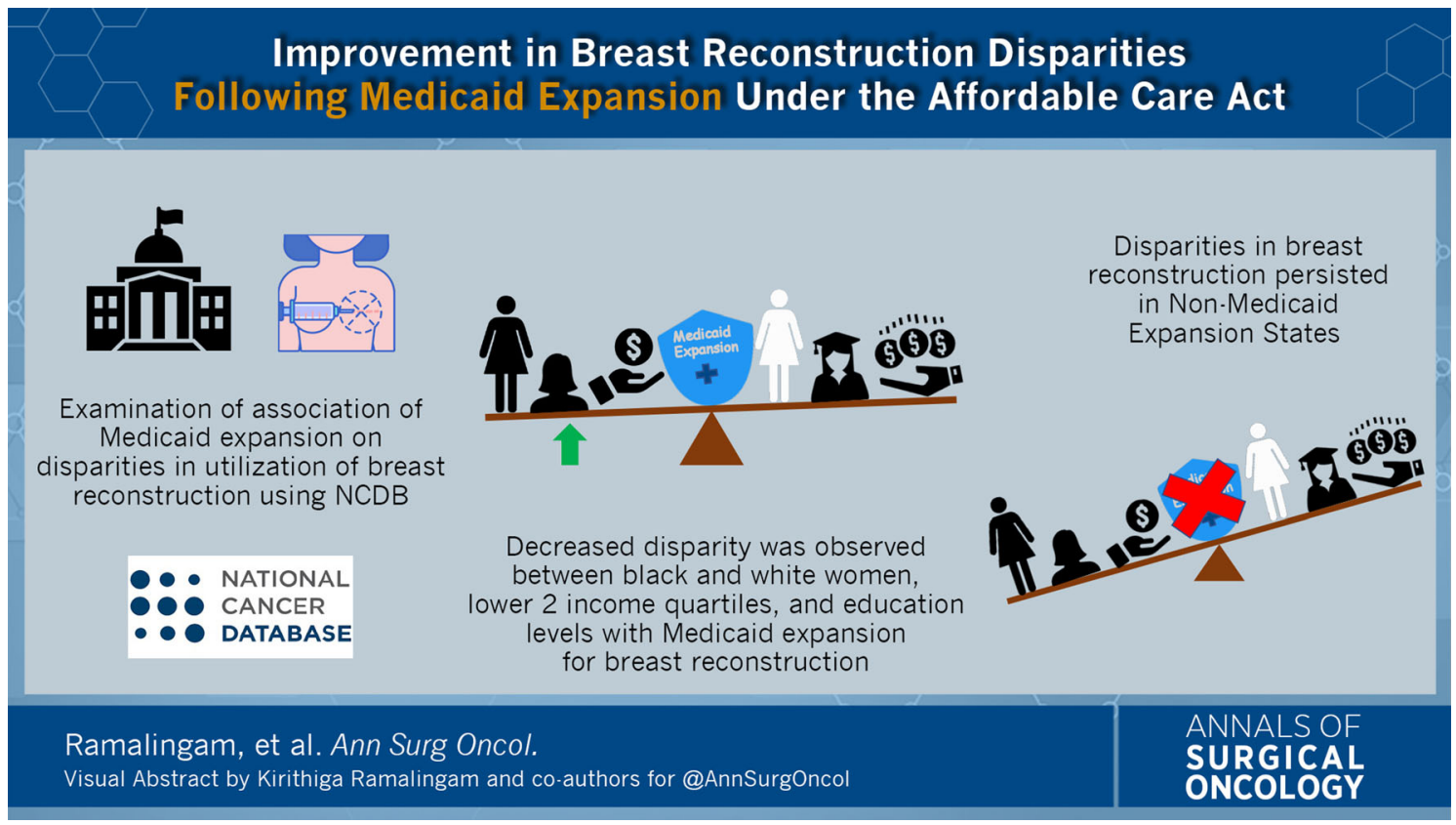

(C) Society of Surgical Oncology 2021

Published Online: 12 August 2021

S. S. Lum, MD

e-mail: slum@1lu.edu 